\title{
AN EVALUATION OF PEDAGOGICAL METHODS FOR ENGINEERING ETHICS EDUCATION
}

\author{
Amanda Thoo and David S. Strong \\ Queen's University at Kingston, Ontario \\ amanda.thoo@queensu.ca and david.strong@queensu.ca
}

\begin{abstract}
Canadian engineers are expected to uphold high ethical standards as part of their responsibility to the profession and society. This expectation is echoed in the $C E A B$ graduate attributes and in the Ritual of the Calling of an Engineer [1],[2]. It is intended that students learn and develop their knowledge of engineering ethics during their undergraduate program, however, North American research in Engineering Ethics Education (EEE) has identified flaws and called into question the efficacy of the current teaching methods being used. Additionally, there is little empirical evidence available to generate any definite conclusions about the pedagogical nature or the efficacies of different EEE teaching methods.

As an early phase of research on this topic, this paper presents an evaluation of literature to understand the current state of EEE in North America, including current perceptions of EEE methods and alternate models for EEE. A proposed research direction to begin identifying and understanding issues related to the teaching of engineering ethics is discussed.
\end{abstract}

Keywords: CEAB attributes, engineering ethics, teaching methods, engineering ethics education

\section{INTRODUCTION}

Engineering ethics education (EEE) is essential in undergraduate programs due to the high level of responsibility that is typical of the engineering profession. Every Canadian engineering graduate earns the right to wear the iron ring, which itself "... serves as a reminder to the engineer and others of the engineer's obligation to live by a high standard of professional conduct" [1]. Engineers Canada also lists ethics and equity as one of its 12 required competency attributes for engineering graduates [2]. To varying extents, ethics influences many decisions made by engineers. Without sufficient ethical guidelines, mistakes, illegalities, and potentially, even catastrophic failures can occur. There are numerous well-known cases of fatal outcomes as a result of poor or improper engineering decisions or actions, many of which could arguably been avoided if firm ethical principles had been applied. The
NASA Space Shuttle Challenger explosion, the collapse of the Quebec bridge, and the Hyatt Regency walkway collapse are just a few examples of engineering failures that had fatal consequences [3]-[6]. But ethics in engineering is much more pervasive than infamous cases like these. Bribery, conflicts of interest, illegal information acquisition, inappropriate workplace conduct, and other ethical dilemmas are much more typical in the engineering profession [7]-[10]. Situations like these may not often be reported by popular news outlets on a regular basis but still have far reaching consequences, which is why high quality teaching and learning of engineering ethics is vital for engineering students in order to provide a solid foundation to handle the ethical challenges they may experience in their careers.

Engineering Ethics was relatively recently introduced as a required graduate attribute by the Canadian Engineering Accreditation Board (CEAB) and the United States (US) Accreditation Board for Engineering and Technology, Inc. (ABET). Since there was previously little formal inclusion of this topic and given the relatively short time since it became a requirement, the body of knowledge and "best practices" for its instruction are limited. As a result, the instruction of engineering ethics can vary notably across institutions, disciplines, courses, and instructors. In the US, the current most common methods of instruction for engineering ethics are exposure to professional codes, case studies, and/or in-class discussion. There are numerous less common teaching methods such as community engagement projects, games, and interactive online modules. [11]-[15]. However, there is little definitive research to evaluate the efficacy of these EEE methodologies, particularly in the Canadian context. Research conducted within the US EEE system has posited several deficiencies in EEE instruction, and in Canada, there is some indication that similar areas of deficiency exists. Studies from the University of Manitoba and University of Toronto have identified that students see their ethics education as a program weakness [16]-[19].

Given that EEE is such a vital topic, it would stand to reason that for it to be identified as a program weakness should be a major concern for industry, educators, and the public. Students need to be equipped with the tools to respond to ethical dilemmas, just as they need to be 
equipped with the skills to address a technical engineering challenge. If the manner that EEE is taught can be assessed for efficacy and improved accordingly, it would therefore be in the best interest of the public as well as the engineering profession to do so.

Addressing EEE content is not the intended focus of the proposed study; rather, the purpose is to better understand the intricacies of EEE teaching and learning for undergraduate students. The proposed research scope will include evaluating if and why deficiencies in EEE exist, assessing the efficacies of various teaching methods, and determining if and how EEE teaching and learning requires different methodologies than traditional engineering subjects. The study will evaluate the most common practices applied for EEE, as well as a few selected methods that appear to be innovative or unique.

\subsection{Research Questions}

To better understand how and where deficiencies in EEE instruction arise, the specific nature of teaching EEE to undergraduate students, and the nuances and efficacies of each methodology for teaching, this study seeks to answer the following questions.

- What are the deficiencies associated with the current state of EEE in Canada? To what extent are they associated with EEE instruction, if at all?

- What are the benefits and drawbacks to each of the different EEE teaching methods? Under what context might they be more appropriate?

- How might EEE teaching practices be better designed and structured to serve today's undergraduate engineering students?

\section{DEFINITIONS}

The terms engineering ethics and engineering ethics education are not clearly defined in the literature. Therefore, the following definitions apply for the purpose of this study.

\subsection{Engineering Ethics}

Ethics itself is broad topic that spans multiple fields, and "to act ethically" is often subjective and dependant on situational context, personal positions, and professional obligations. To provide guidance for the Canadian engineering profession, Engineers Canada (EC) has developed a set of guiding principles termed as "The Code of Ethics," that serve as the framework for responsible professional practice. EC also clearly states that it would be incorrect to interpret these principles as "a set of 'rules' of conduct intended for passive observance". Instead, professionals should seek to dynamically incorporate the essence of the code into all aspects of their decision making, responding to the needs of their situation. Therefore, the code should not stand as the minimum acceptable standard for engineers, but as the principles to help guide everyday activities [20].

For the purposes of this study, engineering ethics will thusly be defined as:

- the knowledge and understanding of the Engineers Canada's code of ethics and/or equivalent provincial engineering licensure bodies' code of ethics

- application of ethical decision making with the ability to reference codes to justify decisions

- an awareness of ethical duty and the ability to recognize and act when presented with an ethical dilemma in the engineering profession

\subsection{Engineering Ethics Education}

Though there is much opportunity for discussion regarding specific curriculum content in ethics education, this is outside the scope of this research. For the purposes of this study, it will be assumed that core content is unlikely to vary significantly across teaching methods. Rather, the facets of content to be addressed will emphasize principles relating to engineering ethics and will be developed as the study progresses. This study will focus on different specific pedagogical methods used to teach engineering ethics content to students, whether its broader delivery method is in a stand-alone course, embedded as part of a broader course, or other delivery method. This approach is partly based on prior research such as May and Luth's 2011 paper, which indicated that stand alone courses were not superior to embedded courses. The majority of variables they investigated did not appear to be significantly influenced by varying delivery methods [21].

\section{LITERATURE REVIEW}

The literature that serves as a framework for this study will investigate the current state of EEE in North America as well as its prior history. Preliminary literature investigating perceptions of EEE, and different methodologies for teaching engineering ethics will be used to better understand the intricacies of EEE, and to assess currently reported strengths and weaknesses thereof.

\subsection{The Current State of EEE in North America}

Ethics education has taken many forms over the decades and continues to evolve in the present day. In 1997 ABET developed their Engineering Criteria 2000 (EC2000), commonly referred to as ABET 2000 [22]. These accreditation criteria and processes sought to evaluate the learning outcomes of engineering programs to ensure students were graduating with the competencies required 
for successful professional engineering practice [23]. Professional ethics and the ability to apply it to engineering scenarios was included in the ABET requirements and was similarly incorporated into the graduate attributes introduced by CEAB approximately a decade later. It is therefore not surprising that the bulk of research literature available EEE is based on US schools and programs, given their earlier accreditation requirement for this content. However, since both ABET and CEAB have very similar wording with respect to competency expectations, it is reasonable to assume that US based research on this topic is relatively transferrable to the Canadian context.

A 1997 study by Lynch provides an overview of the ethics programs at the top ten engineering schools in the US at the outset of the ABET 2000 accreditation requirements. To ensure compliance with the ABET 2000 requirements, ethics was becoming more prominent for undergraduate students and was often approached as an add-on, rather than a structured discipline within engineering. Lynch outlines the organizational structure of the EEE interventions in terms of whether they are standalone courses or ethics embedded within other curriculum content. At the time, new approaches to EEE involved transitioning away from moral theory to a case-based approach. Lynch states that the consensus had shifted to emphasizing the importance of using realistic cases focusing on practical actions engineers could take, rather than focusing on abstract moral dilemmas. He adds that references to ethics codes may be used to supplement this approach [24]. Other studies that came out of this period in the late 90's echo similar themes [25]-[29]. A nonempirical study by Rabin in 1998 explores the what, why and how of teaching engineering ethics in the US, with examples of ethics curricula and models from a few select US schools. He posits that "students need 'drilling' on the issues via case study analyses" [27]. Herkert also reiterates the prevalence of case studies in EEE in his 2000 research study, noting that that evolution of EEE in the US revolves primarily around case studies with exposure to professional codes, occasionally supplemented by an introduction to moral theory [26]. This remained the prevalent way of teaching EEE for the next 15 years, as Hess and Fore observe in their systematic literature review on US engineering ethics interventions. Their study investigated the nature of engineering ethics interventions by systematically analysing articles from 2000 to 2015, organizing them to present the current state of US engineering ethics interventions. Their results state that the most common teaching methods for engineering ethics was to expose students to codes/standards, case studies, and discussion activities [11]. Their findings also indicated that after over a decade since the ABET 2000 criteria were established, there was still limited empirical research on engineering ethics education within the US and with the large variations across interventions, the "best practices" of teaching EEE were still not established. The lack of understanding regarding EEE is also present to an even greater extent in Canada, given the introduction of graduate attribute accreditation a decade after the US, and the relatively few Canadian research studies on EEE.

\subsection{Researcher Perceptions of EEE in North America}

As one of the earlier proponents of understanding EEE efficacy, Colby and Sullivan drew from observational site visits in 2008 to build a picture of EEE effectiveness across several US schools. Common issues regarding pedagogical practices they detail relate to the non-systematic nature of EEE within and across schools. As there is still a limited body of knowledge surrounding EEE and its best practices, each school dictates the way ethics is incorporated into their curriculum. Their research indicated that the teaching of EEE varied school by school, but also varied interdepartmentally within schools. Each instructor selected the curricula and teaching methods they believed to be the most well-suited and as a result, students often received different EEE instruction. Colby and Sullivan then question how comprehensive EEE can be when both the teaching and curricula of EEE vary both across and within schools. They then address the use of case discussions as the central pedagogy of engineering ethics, pointing out that the issue with this is that it often simplifies issues and does not allow students to struggle to assess the trade-offs in engineering decision making. Additionally, the use of case studies often makes choices appear obvious, when in reality, consequences may only become clear after the decision has been made. They state, therefore, that this method does not help students develop the skills to identify and address potential problems before it is too late [30]. Bucciarelli's 2007 paper iterates similar ideas, pointing out that a single pedagogical focus, such as only using specific case studies for EEE, runs the risk of deflecting attention away from the complex and varied nature of engineering work, leaving students with the impression that ethical decisions are obvious or simple [31].

Herkert (2000) had also identified issues with using high profile case studies, suggesting that although potentially useful for student engagement, they can draw attention away from much more common and mundane ethical dilemmas that are more likely to be encountered in engineering practice. He adds that though more commonplace case study development is underway, there is still a lack of "good" case examples being available. Herkert adds that cases showing sound ethical judgements need not end with negative consequences to the party acting ethically [26].

In 2004, Newberry also challenged the current state of EEE, citing his own anecdotal evidence and the work of colleagues to propose that much of ethical instruction is 
only superficially effective, providing students with knowledge of codes, but not engaging them emotionally. He suggests that in-class discussions on cases and other topics may appear lively, but end of year survey data indicated that students did not find the ethics portion effective, interesting, or useful [32].

$\mathrm{Li}$ and $\mathrm{Fu}$, in their 2010 paper, propose the use of a systematic approach to determining what and how to teach engineering ethics. They too indicate that the current teaching of engineering ethics relies too much on microethics and oversimplified case studies. They also point out a lack of differentiation between the instructional and delivery method in application, which could result in a missed opportunity to identify the most appropriate instructional strategy for the given content [12].

From a Canadian standpoint, Roncin's 2013 paper summarized the Canadian EEE research at that point in time, pointing out the issues inherent with the format of introducing students to codes and superficial case studies, reiterating similar points as other researchers have done, and arguing that this format limits the breadth of what the reality of engineering ethics is [33].

\subsection{Student Perceptions of EEE in North America}

One of the most specific indicators that has appeared in Canadian EEE research can be seen in Cicek and Labossiere's three-year study at the University of Manitoba on mechanical engineering student perceptions of graduate attribute competencies. Though not the only identified program weakness, Ethics and Equity were consistently ranked by students as one of the greatest program and personal weaknesses out of all 12 graduate attributes over the three years. During focus groups, students identified a lack of education and opportunities for professionalism and ethics, among other identified program issues. [16]-[18].

Rottman et al.'s study at the University of Toronto reported that students had mixed opinions about the effectiveness of their ethics education, but still listed it as a highly important skill. There was a gap between what students thought about the effectiveness of their engineering ethics education and how important they perceived it to be. Rottman et al. use this to challenge the assumption that the main barrier to effective EEE lies with student disinterest in the topic of engineering ethics [19].

\subsection{Alternate EEE Intervention Models}

EEE interventions can fill a broad range of pedagogical teaching methods. Roleplay, simulations, and games are all examples of less common methods for teaching EEE. Hess and Fore analysed EEE research papers published from 2000-2015 and categorized them to provide an overview of
EEE during this 15-year span. Through this, they named 16 different pedagogical methods for EEE. These include methods discussed previous as well as interventions such as peer mentoring, community engagement, and individual written assignments [11]. Given there is little empirical evidence to compare the most common pedagogical methods, there is even less research conducted on the efficacy of these relatively uncommon methods. Most research related to these approaches tends to be focused on the development of a new EEE tool or method, rather than the efficacy compared to more traditional EEE practices.

As technology and the use of the internet become more advanced and pervasive in society, two additional EEE methods are also beginning to appear. One of these is webbased instruction. In 2004, Cummings and Lowe present their development of an online engineering ethics class, created in part to address a need to create a more time- and effort-efficient course for incoming transfer students. They describe how the operation of the course was implemented through online modules, quizzes and assignments, and state that the completely online course provided valuable opportunities for accessibility and archival properties. However, they also state that the general nature of online accessibility, whether in a traditional or online classroom, lends itself to the risk of plagiarism, which they admit was an issue in the first two years of the course [15].

Combining internet accessibility with technology to create interactive simulations is also another approach to EEE that has occurred in recent years. One example of this is reported in Chung and Alfred's 2008 paper, where they describe their design and development of an internet based interactive Simulator for Engineering Ethics Education (SEEE). The simulator focuses on putting students in a first-person "choose your own adventure" model in which students are provided with choices and branches to follow, based on their decisions [14].

Although both methods outlined above are examples of new pedagogical models for EEE, neither publication presents empirical data to assess learning efficacy versus traditional EEE methods. The only comparative data presented was in Chung and Alfred's paper, which was stated to be a limited comparison between their interactive simulator and a "conventional" online teaching model.

\section{PROPOSED DIRECTION OF STUDY}

The goals for the proposed research study are to better understand the nuances to common EEE methods, to establish a methodology for evaluating EEE success so that deficiencies can be identified, and to obtain direct comparison data for EEE efficacy for a specific demographic of engineering students. At this point, the background and methodology for the study are being developed, drawing from existing research methods and instruments of measuring efficacy of ethics programs, as 
well as understanding how students' conduct their ethical decision-making in order to identify potential links between teaching methods and how they engage students (or not) and influence their ethical decision making (or not).

Although a specific research plan and/or instrument has not yet been developed for this study, the proposed approach will focus on students in their 1st and/or 2nd year of their engineering program, preferably prior to any significant engineering ethics training in a formal environment.

The proposed research is expected to use a mixedmethods approach, combining qualitative data on aspects like student perceptions of EEE with quantitative data on factors such as statistical comparison data between EEE methods. Pre- and post-questionnaires, ethical baseline tests, and other ethical measurement tools are intended to be used to assess the efficacies of each EEE intervention. Diversity in these interventions is a necessity of the study and could be accomplished by enacting different EEE interventions with students in one location, and/or by using data from multiple universities with different EEE methodologies.

One aspect of the research methodology under consideration is comparing student results to 'experienced' engineers, ${ }_{\overline{1}}$ and observing the similarities or differences between them. Experienced engineers could be those with several years or more industry experience, faculty, and/or engineers belonging to engineering ethics organizations. This could provide an opportunity to compare postintervention students with those with real-world engineering ethics experience.

\section{CONCLUSIONS}

A thorough literature review performed as the foundation for the proposed study indicates that EEE has undergone little change since the late 90 's, perhaps due to the lack of empirical evidence on the efficacy of various EEE methods. Much of the development of current "best practices" appears to have developed over time, based on instructors' observations and anecdotal student feedback. The research studies that exist on this topic point out that EEE lacks efficacy, and have identified flaws in current teaching methods, but little empirical data has been used to develop specific conclusions on the nature of EEE deficiencies. New methods for EEE have been proposed and developed, but most lack empirical evidence to support the efficacy of their methods, particularly in comparison with other forms of EEE.

A firm foundation in engineering ethics is not just desirable, but a requirement for ethically sound professional engineering practice. Foundational ethical standards for such practice needs to be developed at the undergraduate level, not only to comply with accreditation requirements, but also to ensure that students are well prepared for the engineering workplace. If the methods currently used to teach students can be assessed for their efficacy, it is anticipated that EEE can be optimized accordingly, providing the potential for higher and more consistent engineering ethics standards upon graduation.

It is the intention of this study moving forward, to provide a thorough overview of current engineering ethics education practices to better understand the nuances to common EEE methods and to develop new empirical evidence regarding the efficacies of several EEE methods, thus providing a significant step toward optimal teaching and learning in this field.

\section{References}

[1] "Background | The Iron Ring." [Online]. Available: http://www.ironring.ca/background.php. [Accessed: 05-Dec-2019].

[2] Canadian Engineer Accreditation Board, "Graduate Attributes," Engineers Canada, 2016. [Online]. Available:

https://engineerscanada.ca/sites/default/files/Graduat e-Attributes.pdf.

[3] "Challenger disaster | Summary, Date, Cause, \& Facts," Encyclopedia Britannica. [Online]. Available:

https://www.britannica.com/event/Challengerdisaster. [Accessed: 15-Feb-2020].

[4] "The Hyatt Regency Walkway Collapse | ASCE." [Online]. Available: https://www.asce.org/questionof-ethics-articles/jan-2007/. [Accessed: 15-Feb2020].

[5] R. D. Marshall et al., "Investigation of the Kansas City Hyatt Regency Walkways Collapse. (NBS BSS 143)," May 1982.

[6] Pearson Cynthia and Delatte Norbert, "Collapse of the Quebec Bridge, 1907," Journal of Performance of Constructed Facilities, vol. 20, no. 1, pp. 84-91, Feb. 2006, doi: 10.1061/(ASCE)08873828(2006)20:1(84).

[7] "Standards and Anti-Competitive Behavior: The Hydrolevel Case | ASCE." [Online]. Available: https://www.asce.org/question-of-ethics-articles/feb2011/. [Accessed: 15-Feb-2020].

[8] "SEC.gov | SEC Charges Two Friends With Insider Trading Ahead of Impending Acquisition.” [Online]. Available: https://www.sec.gov/news/pressrelease/2014-65. [Accessed: 15-Feb-2020].

[9] "SNC-Lavalin Pleads Guilty In Libya Bribery Trial," HuffPost Canada, 18-Dec-2019. [Online]. Available: https://www.huffingtonpost.ca/entry/snc-lavalinguilty-plea_ca_5dfa526de4b0d6c84b779e54. [Accessed: 15-Feb-2020]. 
[10] "Engineering Law and Professional Liability: Case Studies | Department of Electrical and Computer Engineering | University of Waterloo." [Online]. Available:

https://ece.uwaterloo.ca/ dwharder/PPE/Part_B_cas es/. [Accessed: 15-Feb-2020].

[11] J. L. Hess and G. Fore, "A Systematic Literature Review of US Engineering Ethics Interventions," Sci Eng Ethics, vol. 24, no. 2, pp. 551-583, Apr. 2018, doi: 10.1007/s11948-017-9910-6.

[12] J. Li and S. Fu, "A systematic approach to engineering ethics education," Sci Eng Ethics, vol. 18, no. 2, pp. 339-349, Jun. 2012, doi: 10.1007/s11948-010-9249-8.

[13] C. Chung, "Comparison of Cross Culture Engineering Ethics Training Using the Simulator for Engineering Ethics Education," Sci Eng Ethics, vol. 21, no. 2, pp. 471-478, Apr. 2015, doi: 10.1007/s11948-014-9542-z.

[14] C. A. Chung and M. Alfred, "Design, Development, and Evaluation of an Interactive Simulator for Engineering Ethics Education (SEEE)," Sci Eng Ethics, vol. 15, no. 2, pp. 189-199, Jun. 2009, doi: 10.1007/s11948-008-9109-y.

[15] M. L. Cummings and J. Lo, "Globalizing engineering ethics education through Web-based instruction," in 2004 International Symposium on Technology and Society (IEEE Cat. No.04CH37548), 2004, pp. 9295, doi: 10.1109/ISTAS.2004.1314331.

[16] J. Cicek, P. Labossiere, and S. Ingram, "Examining Fourth Year Engineering Student Perceptions of Graduate Attribute Competencies: Year Two," Proceedings of the Canadian Engineering Education Association, Aug. 2015, doi: 10.24908/pceea.v0i0.5878.

[17] J. S. Cicek, P. Labossiere, and S. Ingram, "Examining Fourth Year Mechanical Engineering Student Perceptions of Graduate Attribute Competencies: Year Three," Proceedings of the Canadian Engineering Education Association (CEEA), Aug. 2015, doi: 10.24908/pceea.v0i0.5795.

[18] J. S. Cicek, P. Labossiere, and D. Mann, "Surveying Fourth Year Engineering Student Perceptions of Graduate Attribute Competencies," Proceedings of the Canadian Engineering Education Association (CEEA), Jun. 2013, doi: 10.24908/pceea.v0i0.4857.

[19] C. Rottmann, D. Reeve, R. Sacks, and M. Klassen, "Engineering ethics education: More than a CEAB requirement," 2015.

[20] "Public Guideline on the code of ethics | Engineers Canada." [Online]. Available: https://engineerscanada.ca/publications/publicguideline-on-the-code-of-ethics\#-fundamentalprinciples. [Accessed: 06-Feb-2020].
[21] D. R. May and M. T. Luth, "The Effectiveness of Ethics Education: A Quasi-Experimental Field Study," Sci Eng Ethics, vol. 19, no. 2, pp. 545-568, Jun. 2013, doi: 10.1007/s11948-011-9349-0.

[22] "History | ABET." [Online]. Available: https://www.abet.org/about-abet/history/. [Accessed: 06-Feb-2020].

[23] "Criteria for Accrediting Engineering Programs, 2018 - 2019 | ABET." [Online]. Available: https://www.abet.org/accreditation/accreditationcriteria/criteria-for-accrediting-engineeringprograms-2018-2019/. [Accessed: 06-Feb-2020].

[24] W. T. Lynch, "Teaching engineering ethics in the United States," IEEE Technology and Society Magazine, vol. 16, no. 4, pp. 27-36, Winter 1997, doi: 10.1109/44.642561.

[25] C. E. Harris, M. Davis, M. S. Pritchard, and M. J. Rabins, "Engineering Ethics: What? Why? How? And When?," Journal of Engineering Education, vol. 85, no. 2, pp. 93-96, 1996, doi: 10.1002/j.21689830.1996.tb00216.x.

[26] J. R. Herkert, "Engineering ethics education in the USA: Content, pedagogy and curriculum," European Journal of Engineering Education, vol. 25, no. 4, pp. 303-313, Dec. 2000, doi: 10.1080/03043790050200340.

[27] M. J. Rabins, "Teaching engineering ethics to undergraduates: Why? What? How?," SCI ENG ETHICS, vol. 4, no. 3, pp. 291-302, Sep. 1998, doi: 10.1007/s11948-998-0021-2.

[28] C. Whitbeck, "Teaching ethics to scientists and engineers: Moral agents and moral problems," Sci Eng Ethics, vol. 1, no. 3, pp. 299-308, Sep. 1995, doi: 10.1007/BF02628805.

[29] W. T. Lynch and R. Kline, "Engineering Practice and Engineering Ethics," Science, Technology, \& Human Values, vol. 25, no. 2, pp. 195-225, Apr. 2000, doi: $10.1177 / 016224390002500203$.

[30] A. Colby and W. M. Sullivan, "Ethics Teaching in Undergraduate Engineering Education," Journal of Engineering Education, vol. 97, no. 3, pp. 327-338, 2008, doi: 10.1002/j.2168-9830.2008.tb00982.x.

[31] L. L. Bucciarelli, "Ethics and engineering education," European Journal of Engineering Education, vol. 33, no. 2, pp. 141-149, May 2008, doi: $10.1080 / 03043790801979856$.

[32] B. Newberry, "The dilemma of ethics in engineering education," SCI ENG ETHICS, vol. 10, no. 2, pp. 343-351, Jun. 2004, doi: 10.1007/s11948-004-00308.

[33] A. Roncin, "Thoughts on Engineering Ethics Education in Canada," Proceedings of the Canadian Engineering Education Association (CEEA), Jun. 2013, doi: 10.24908/pceea.v0i0.4909. 